\title{
$\bullet$ IJCRR \\ Section: Healthcare \\ Incidence, Clinical Features and Complications in Patients with Appendicolith Associated Acute Appendicitis
} ISI Impact Factor (2019-20): 1.628 IC Value (2019): 90.81 SJIF (2020) $=7.893$

(c) (i) (8)

\author{
Mishra T, Patra GT, Vardhan A, Cheleng AG, Samal D* \\ Department of General Surgery, IMS \& SUM Hospital, Siksha O Anusandha (Deemed to be) University, Bhubaneswar, Odisha, India.
}

\section{ABSTRACT}

Introduction: Acute appendicitis is one of the most frequent causes of abdominal pain in patients presenting to the emergency department (ED) who need surgical treatment with an incidence of 100 to 200 cases per 100,000 person-years. In this study, we have decided to see the incidence, clinical features and complications associated with appendicolith associated acute appendicitis in the patients which presented to us with clinical features of acute appendicitis in our tertiary care hospital setup

Objective: To study the incidence, clinical features and complications associated with appendicolith associated acute appendicitis in the patients which presented to us with clinical features of acute appendicitis in our tertiary care hospital (IMS \& SUM Hospital).

Methods: This is a prospective study, carried out in IMS \& SUM Hospital, a tertiary care hospital, Odisha during the period between April 2019 to October 2020. All the patients presenting to the Emergency Department (ED) with symptoms suggestive of Acute Appendicitis were included in this study.

Results: Of the 200 patients who underwent appendectomy, 63 (31.5\%) patients were $\leq 17$ years of age. Following appendicectomy, appendicoliths were found in 66 (33\%) appendicectomy specimens. The sensitivity of trans abdominal ultrasonography to detect appendicolith to be $53.03 \%$ with a positive predictive value and specificity to be $67.30 \%$ and $87.31 \%$ respectively. Overall, complicated appendicitis was more commonly seen in patients with appendicolith as compared to patients without appendicolith $(69.7 \%$ vs $23.9 \%)$, and this value is significant $(P<0.001)$.

Conclusion: Acute appendicitis is more common in the pediatric age group (0-17 years) as compared to the adult population. Ultrasonography has very low sensitivity and is a poor predictor of appendicoliths in patients presenting with acute appendicitis. Appendicitis with appendicolith results in higher incidences of complicated appendicitis. Thus, these patients should undergo appendicectomy rather than conservative management.

Key Words: Acute Appendicitis, Appendicolith, Complicated Appendicitis, Appendectomy

\section{INTRODUCTION}

Acute appendicitis is one of the most frequent causes of abdominal pain in patients presenting to the emergency department (ED) who need surgical treatment with an incidence of 100 to 200 cases per 100,000 person-years. ${ }^{1}$ Acute appendicitis can present as uncomplicated or complicated variants. Complicated appendicitis is traditionally defined as appendicitis complicated by the presence of gangrene, perforation, peri appendicular abscess, generalized peritonitis. The most common cause of Appendicitis is luminal obstruction by appendicolith. ${ }^{2}$
Appendicolith, also known as faecolith/coproliths/stercoliths is composed of faecal concretions or pellets, calcium phosphates, bacteria and epithelial debris and can lead to luminal obstruction followed by appendicitis. They can be seen in around $10 \%$ of patients with acute appendicitis. ${ }^{3}$ Presence of appendicolith has been identified as an independent prognostic factor for failure of conservative management in cases of uncomplicated acute appendicitis and it has also been linked with increased incidence of complicated appendicitis. ${ }^{4-8}$ The detection of appendicoliths in cases of acute appendicitis have increased due to the better imaging modalities and are also being detected in patients without inflammatory changes in the appendix.

\section{Corresponding Author:}

Dr. Debasish Samal, Professor, Department of General Surgery, IMS \& SUM Hospital, Siksha O Anusandha (Deemed to be) University, Bhubaneswar, Odisha, India; Mob: 9438384284; Email: dr.dsamalindia@gmail.com

ISSN: 2231-2196 (Print) ISSN: 0975-5241 (Online)

Received: $04.08 .2020 \quad$ Revised: 13.10 .2020

Accepted: 24.12 .2020

Published: 19.05 .2021 
In this study, we have decided to see the incidence, clinical features and complications associated with appendicolith associated acute appendicitis in the patients who presented to us with clinical features of acute appendicitis in our tertiary care hospital setup (IMS \& SUM Hospital).

\section{MATERIALS AND METHODS}

This is a prospective study, carried out in IMS \& SUM Hospital, a tertiary care hospital, Odisha during the period between April 2019 to October 2020. All the patients presenting to the Emergency Department (ED) with symptoms suggestive of Acute Appendicitis were included in this study.

Demographic data collected included: age and sex. History of present illness data collected included duration of the symptoms and the presence/absence of nausea, vomiting, anorexia, diarrhoea, migration to the right lower quadrant (RLQ) and similar previous episodes. Duration of symptoms was defined as the time since the onset of symptoms to presentation to the ED. Physical examination data collected included the first recorded temperature (Fahrenheit), heart rate, systolic blood pressure (SBP), Alvarado score, and the presence/absence of RLQ tenderness, diffuse abdominal tenderness, RLQ rebound tenderness, diffuse abdominal rebound tenderness, Rovsing sign, Obturator sign, and Psoas sign, as documented by the surgeon or postgraduate resident. ${ }^{9}$ Laboratory data collected included the first recorded $\mathrm{ED}$ value for total WBC and percentage of polymorphonuclear cells. Radiological data collected included ultrasonography (USG). Appendicolith on USG along with uncomplicated or complicated appendicitis (gangrene, perforation, peri-appendicular abscess, generalized peritonitis) was noted.

Management data included Antibiotics and appendectomy (Open or Laparoscopic). Intraoperative findings were noted. After an appendectomy, the specimen was cut open to check for the presence of intraluminal appendicolith and sent for histopathological study.

\section{RESULTS}

Of the 200 patients who underwent appendectomy, 63 $(31.5 \%)$ patients were $\leq 17$ years of age and the rest 137 (68.5\%) patients were of 18 years or more. Following appendicectomy, appendicoliths were found in $66(33 \%)$ appendicectomy specimens. The incidence of appendicolith in paediatric age group was found to be $42.9 \%$ ( 27 patients) and $28.4 \%$ (39 patients) in adult population which was significant $(\mathrm{P}$-value $=0.044)$ [Table 1 and 3$]$.

Out of 66 patients with appendicolith, 34 patients $(51.5 \%)$ presented with fever of more than $101^{\circ} \mathrm{F}$ whereas only 31 patients (23.1\%) without appendicolith had fever more than $101^{\circ} \mathrm{F}$
[Table 2]. Vomiting was associated with 57.5\% (38 patients) of patients with appendicolith as compared to only $36.5 \%$ (49 patients) of patients without appendicolith [Table 2]. Generalized guarding was present in $12.1 \%$ (8 patients) of patients with appendicolith as compared to $2.2 \%$ (3 patients) without it [Table 2]. A history of a similar episode in the past was seen in $34.8 \%$ (23 patients) of patients with appendicolith and 14.9\% (20 patients) in patients without [Table 2].

Preoperative transabdominal ultrasonography was done in all the 200 patients, revealing appendicolith in 52 patients. The results of the pre-operative ultrasonography were compared with the postoperative detection of appendicolith in the appendix specimen. This revealed the sensitivity of trans abdominal ultrasonography to detect appendicolith to be $53.03 \%$ with a positive predictive value and specificity to be $67.30 \%$ and $87.31 \%$ respectively [Table 3].

Intraoperatively, $22.7 \%$ of patients with appendicoliths had perforation as compared to $5.2 \%$ of patients without (P-value $<0.001$ ) and $25.7 \%$ of patients had a gangrenous appendix with appendicolith vs $8.9 \%$ patients without appendicolith. Overall, complicated appendicitis was more commonly seen in patients with appendicolith as compared to patients without appendicolith $(69.7 \%$ Vs $23.9 \%)$, and this value is significant (P-value $<0.001)$ [Table 4].

\section{DISCUSSION}

Acute appendicitis presents in the emergency department either as uncomplicated or complicated varieties. Most of the cases $(70-80 \%)$ are uncomplicated. In the past few years, the incidence of uncomplicated acute appendicitis is declining, whereas the incidence of complicated appendicitis remains unchanged..$^{9,10}$ Early diagnosis and surgical resection of the appendix have been the mainstay for the treatment of acute appendicitis for many years. However, there is a paradigm shift in the approach and management of acute appendicitis with recent evidence showing that early surgical intervention is not always mandatory and acute appendicitis can be managed effectively with proper dosage of antibiotics. ${ }^{11,12}$ Many studies in the past concluded appendicolith as an independent prognostic risk factor for failure of non-surgical management of uncomplicated acute appendicitis and also showed its association with the increase in the incidences of appendiceal perforations. ${ }^{4-8}$

Older studies supported the theory of Appendicolith's being the main cause of obstruction, leading to appendicitis. Collins described the prevalence of appendicolith as $44.25 \%$ in 71,000 specimens. ${ }^{13}$ Study of Collins included 12,119 prophylactic appendicectomies and 6,409 post-mortem specimens but only 11,961 cases of simple appendicitis. Since prevalence in each category was not calculated, conclusions about the association of appendicolith with appendicitis cannot be made. 
Various other studies have also shown appendicolith prevalence of $33-44 \%$ in cases of appendicitis. ${ }^{14-16}$ However, larger series studies are done after 1970, show a decrease in the prevalence of appendicolith with the percentage ranging between $1.5 \%$ to $15 \% \cdot{ }^{17-23} \mathrm{~A}$ study by Jonas et all. (sample size $<100$ cases) in the post-1970s era, showed the prevalence of appendicolith was $52 \% .{ }^{24}$ In the present study, overall appendicolith prevalence was found to be $33 \%$. Previous studies showed the prevalence of appendicolith in the paediatric age group ( $\leq 17$ years) with acute appendicitis to be between 19$65 \% .{ }^{6,25,26}$ Similar results were found in our study with $42.9 \%$ in the paediatric age group versus $28.4 \%$ in adults having appendicoliths in patients of acute appendicitis.

Historically, appendicolith has been associated with clinically severe appendicitis. In our study fever of more than $101^{\circ} \mathrm{F}$ was seen in $51.5 \%$ of patients with appendicolith as compared to only $23.1 \%$ of patients without appendicolith. Vomiting was more associated with acute appendicitis with appendicolith as compared to only appendicitis $(57.5 \%$ vs $36.5 \%$ ). Similarly, generalized guarding/ rigidity was seen in $12.1 \%$ of appendicolith positive patients as compared to $2.2 \%$ of patients without appendicolith. History of the similar episode of pain in the RIF was present in $34.8 \%$ of patients with appendicolith as compared to $14.9 \%$ of patients without appendicolith, suggesting, the attacks of appendicitis tend to recur in patients of an appendicolith, if not treated with appendicectomy in the first instance.

In our study, $22.7 \%$ of the patients with appendicolith presented with a perforated appendix as compared to only 5.2\% of patients without appendicolith. These results are similar to the findings of Fitz and Wangensteen. ${ }^{27,28}$ Studies in the past show Transabdominal ultrasonography (USG) to have a sensitivity of $86 \%-95 \%$ and specificity ( $78 \%-84 \%)$ in diagnosing acute appendicitis. ${ }^{29}$ But computed tomography (CT) is more sensitive for diagnosing appendicolith in patients with appendicitis as compared to ultrasonography. CT scan is not done routinely for all the cases of acute appendicitis, so in our study, we have tried to find out the sensitivity, positive predictive value and specificity of ultrasonography in detecting appendicolith in a patient with acute appendicitis. In our study, the sensitivity, positive predictive value and specificity of USG in detecting appendicolith were found to be $53.03 \%, 67.30 \%$ and $87.31 \%$ respectively.

\section{CONCLUSION}

Based on the study findings, we can conclude that appendicolith in cases presenting with acute appendicitis is more common in the pediatric age group (0-17 years) as compared to the adult population. Acute appendicitis patients with appendicolith have a higher chance to develop a fever of more than $101^{\circ} \mathrm{F}$ and have episodes of vomiting as compared to patients without appendicolith. History of similar episodes of pain in the RLQ in the past, managed conservatively, is more common in patients of acute appendicitis with appendicolith. Appendicitis with appendicolith results in higher incidences of complicated appendicitis. Thus, these patients should undergo appendicectomy rather than conservative management. Ultrasonography has very low sensitivity and is a poor predictor of appendicoliths in patients presenting with acute appendicitis.

Conflict of Interest: There is no conflict of interest among the authors.

Author Contribution: Dr.Debasish Samal and Dr.Tejaswi Mishra have contributed in performing the surgeries, concept, study design, data analysis, statistical analysis and manuscript preparation, Dr.Godalu Trinath Patra contributed in performing the surgeries manuscript editing and manuscript review. Dr. Ayush Vardhan and Dr.Ankur Gogoi Cheleng have contributed towards literature search, data acquisition, manuscript editing.

Funding: Nil

\section{REFERENCES}

1. Ferris M, Quan S, Kaplan BS, Molodecky N, Ball CG, Chernoff GW, et al. The Global Incidence of Appendicitis. Ann Surg. 2017;266(2):237-241.

2. Prystowsky JB, Pugh CM, Nagle AP. Appendicitis. Curr Probl Surg. 2005;42(10):694-742.

3. Teke Z, Kabay B, Erbiş H, Tuncay ÖL. Appendicolithiasis causing diagnostic dilemma: A rare cause of acute appendicitis (report of a case). Ulus Travma ve Acil Cerrahi Derg 2008;14(4):323-325.

4. Mahida JB, Lodwick DL, Nacion KM, Sulkowski JP, Leonhart $\mathrm{KL}$, Cooper JN, et al. High failure rate of nonoperative management of acute appendicitis with an appendicolith in children. J Pediatr Surg 2016;51(6):908-911.

5. Shindoh J, Niwa H, Kawai K, Ohata K, Ishihara Y, Takabayashi $\mathrm{N}$, et al. Predictive factors for negative outcomes in initial nonoperative management of suspected appendicitis. J Gastrointest Surg 2010;14(2):309-314.

6. Alaedeen DI, Cook M, Chwals WJ. Appendiceal fecalith is associated with early perforation in pediatric patients. J Pediatr Surg 2008;43(5):889-892.

7. Yoon HM, Kim JH, Lee JS, Ryu JM, Kim DY, Lee JY. Pediatric appendicitis with appendicolith often presents with prolonged abdominal pain and a high risk of perforation. World J Pediatr 2018;14(2):184-90.

8. Singh JP, Mariadason JG. Role of the faecolith in modern-day appendicitis. Ann R Coll Surg Engl 2013;95(1):48-51.

9. Bhangu A, Søreide K, Di Saverio S, Assarsson JH, Drake FT. Acute appendicitis: modern understanding of pathogenesis, diagnosis, and management. Lancet 2015;386(10000):1278-1287.

10. Cameron JL CA. Current Surgical Therapy. 10th edit. Philadelphia: Mosby; 2011. 219 p.

11. Styrud J, Eriksson S, Nilsson I, Ahlberg G, Haapaniemi S, Neovius $\mathrm{G}$, et al. Appendectomy versus antibiotic treatment in acute appendicitis. A prospective multicenter randomized controlled 
trial. World J Surg 2006;30(6):1033-1037.

12. Oliak D, Yamini D, Udani VM, Lewis RJ, Vargas H, Arnell T, et al. Nonoperative management of perforated appendicitis without periappendiceal mass. Am J Surg 2000;179(3):177-181.

13. DC Collins. 71,000 Human appendix specimens. a final report, summarizing forty years' study. Am J Proctol 1963;14(December):265-281.

14. Shaw RE. Appendix calculi and acute appendicitis. Br J Surg 1965;52(6):451-459.

15. Felson B. Appendical calculi; incidence and clinical significance. Surgery 1949;25(5)(May):734-737.

16. Steinert R, Hareide I, Christiansen T. Roentgenologic examination of acute appendicitis. Acta Radiol 1943;24(1):13-37.

17. Makaju R, Mohammad A, Shakya A. Acute appendicitis: Analysis of 518 histopathologically diagnosed cases at the Kathmandu University Hospital, Nepal. Kathmandu Univ Med J 2010;8(30):227-230.

18. Andreou P, Blain S DBC. A histopathological study of the appendix at autopsy and after surgical resection. Histopathology 1990; Nov(17(5)):427-431.

19. Marudanayagam R, Williams GT, Rees BI. Review of the pathological results of 2660 appendicectomy specimens. J Gastroenterol 2006;41(8):745-749.

20. Chang AR. An Analysis of the Pathology of 3003 Appendices. Aust NZ J Surg 1981;51(2):169-178.

21. Nitecki S, Karmeli R, Sarr MG. Appendiceal calculi and fecaliths as indications for appendectomy. Surg Gynecol Obstet 1990;171(3):185-188.
22. Forbes GB, Lloyd-Davies RW. The calculous disease of the vermiform appendix. Gut 1966;7(6):583-592.

23. Sgourakis G, Sotiropoulos GC, Molmenti EP, Eibl C, Bonticous $\mathrm{S}$, Monge J, et al. Are acute exacerbations of chronic inflammatory appendicitis triggered by coprostasis and/or coproliths? World J Gastroenterol 2008;14(20):3179-3182.

24. Jones BA, Demetriades D, Segal I, Burkitt DP. The prevalence of appendiceal fecaliths in patients with and without appendicitis. A comparative study from Canada and South Africa. Ann Surg 1985;202(1):80-82.

25. Lowe LH, Penney MW, Scheker LE, Perez R. J, Stein SM, Heller RM, et al. Appendicolith revealed on CT in children with suspected appendicitis: How specific is it in the diagnosis of appendicitis? Am J Roentgenol 2000;175(4):981-984.

26. Fraser N, Gannon C, Stringer MD. Appendicular Colic and the Non-Inflamed Appendix: Fact or Fiction? Eur J Pediatr Surg 2004;14(1):21-24.

27. Fitz RH. Perforating inflammation of the vermiform appendix. Am J Med Sci. 1886;92:321-346.

28. Wangensteen O, Dennis C. experimental proof of the obstructive origin of appendicitis in man. Ann Surg 1939;110(665):629-647.

29. Terasawa T, Blackmore CC, Bent KR. Systematic review: computed tomography and ultrasonography to detect acute appendicitis in adults and adolescents. Ann Intern Med 2004;141(7):537546.

Table 1: Age dependent prevalence of Appendicitis

\begin{tabular}{lccc}
$\begin{array}{l}\text { Age Groups } \\
\text { (in years) }\end{array}$ & Appendicitis with Appendicolith (n=66) & $\begin{array}{c}\text { Appendicitis without } \\
\text { Appendicolith (n=134) }\end{array}$ & p-value \\
\hline $\mathrm{o}-17$ & $27(42.9 \%)$ & $36(57.1 \%)$ & 0.044 \\
$\geq 18$ & $39(28.4 \%)$ & $98(71.6 \%)$ & \multirow{2}{*}{} \\
\hline
\end{tabular}

Table 2: Clinical Features of Appendicitis

\begin{tabular}{lccc} 
Clinical Features & $\begin{array}{c}\text { Appendicitis with } \\
\text { Appendicolith (n=66) }\end{array}$ & $\begin{array}{c}\text { Appendicitis without } \\
\text { Appendicolith (n=134) }\end{array}$ & Total \\
Fever more than $101^{\circ} \mathrm{f}$ & $34(51.5 \%)$ & $31(23.1 \%)$ & 65 \\
Vomiting & $38(57.5 \%)$ & $49(36.5 \%)$ & 87 \\
Localized Guarding / Rigidity & $58(87.8 \%)$ & $131(97.7 \%)$ & 189 \\
Generalized Guarding / Rigidity & $8(12.1 \%)$ & $3(2.2 \%)$ & 11 \\
History of Similar Episode in the Past & $23(34.8 \%)$ & $20(14.9 \%)$ & 43 \\
\hline
\end{tabular}

Table 3: USG Findings in Appendicectomy

\begin{tabular}{lccc} 
USG Findings & $\begin{array}{c}\text { Appendicectomy Specimen Positive } \\
\text { for Appendicolith }\end{array}$ & $\begin{array}{c}\text { Appendicectomy Specimen } \\
\text { Negative for Appendicolith }\end{array}$ & Total \\
USG Positive for Appendicolith & 35 & 17 & 52 \\
USG Negative for Appendicolith & 31 & 117 & 148 \\
Total & 66 & 134 & 200 \\
\hline
\end{tabular}


Table 4: Intra-operative Findings of Appendix in Appendicectomy

\begin{tabular}{lcccc}
$\begin{array}{l}\text { Intra-operative Findings of Ap- } \\
\text { pendix }\end{array}$ & $\begin{array}{c}\text { Appendicitis with Appen- } \\
\text { dicolith } \\
(\mathbf{n}=\mathbf{6 6}, \mathbf{1 0 0} \%)\end{array}$ & $\begin{array}{c}\text { Appendicitis with- } \\
\text { out Appendicolith } \\
(\mathbf{n = 1 3 4 , 1 0 0 \% )}\end{array}$ & $\begin{array}{c}\text { Total } \\
(\mathbf{n}=\mathbf{2 0 0}, \mathbf{1 0 0} \%)\end{array}$ & $\mathbf{p}$-value \\
Inflamed appendix & $20(30.3 \%)$ & $102(76.1 \%)$ & $122(61.0 \%)$ & $<0.001$ \\
Peri-appendicular dense adhesions & $14(21.2 \%)$ & $13(9.7 \%)$ & $27(13.5 \%)$ & 0.025 \\
Gangrenous appendix & $17(25.7 \%)$ & $12(8.9 \%)$ & $29(14.5 \%)$ & 0.002 \\
Perforated appendix & $15(22.7 \%)$ & $7(5.2 \%)$ & $22(11.0 \%)$ & $<0.001$ \\
\hline
\end{tabular}
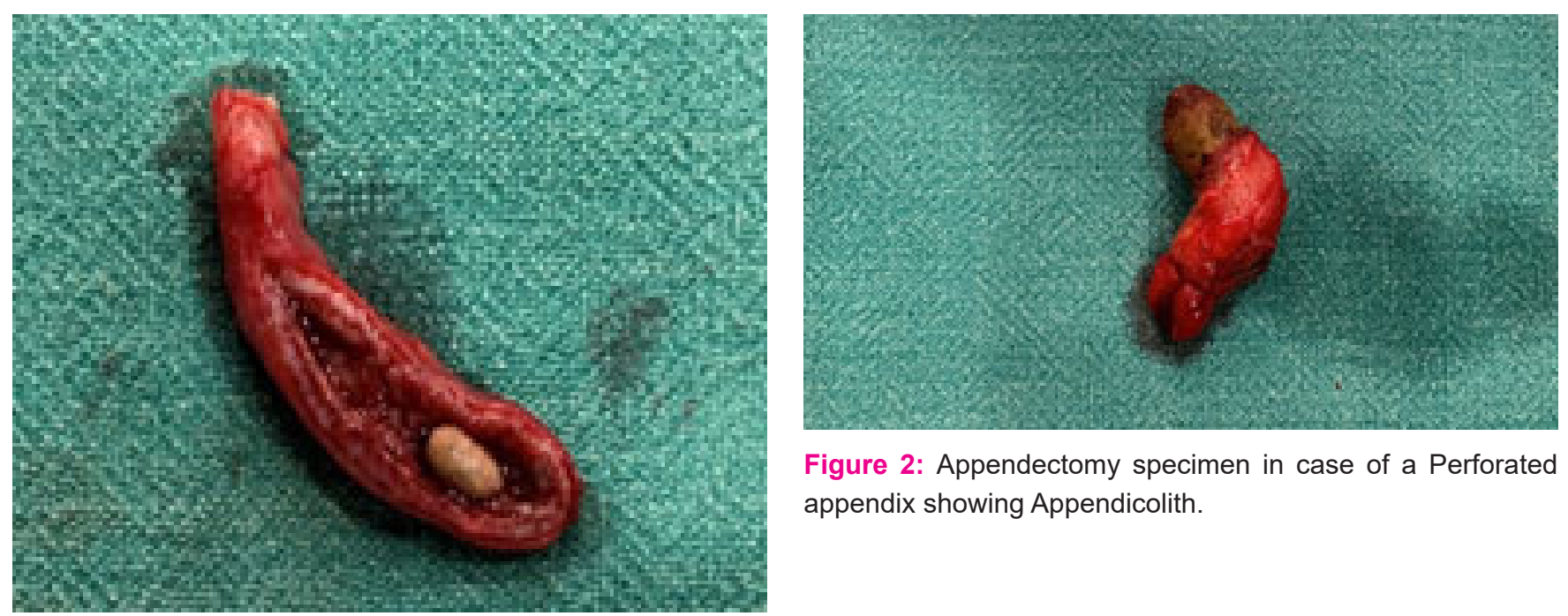

Figure 2: Appendectomy specimen in case of a Perforated appendix showing Appendicolith.

Figure 1: Appendectomy specimen cut open to show Appendicolith 